\title{
Modeling of Intra-System Relationships in the Adaptive Model of the Marine Environment Biochemical Processes
}

\author{
I. E. Timchenko, E. M. Igumnova, S. V. Svishchev* \\ Marine Hydrophysical Institute of RAS, Sevastopol, Russian Federation \\ *sergsvishchev09@gmail.com
}

Purpose. Complexity of biochemical processes in marine environment entails the problem of parameterizing their interactions in constructing the marine ecosystem mathematical models. The aim of the investigation is to simplify solution of this problem by applying the concept of the ecosystem stationary state and the hypothesis on balance of the processes' mutual influence based on the matter balances of biochemical reactions in substance transformations.

Methods and Results. To simplify the ecosystem model, applied is the method of the adaptive balance of causes which now is being developed by the authors. The method equations contain negative feedbacks between the ecosystem model variables and the velocities of their change. These feedbacks stabilize the equations' solutions and make the model adaptive to the external effects on the ecosystem. The concept of the solutions' convergence to the stationary state permitted to propose a simple methods (based on the normalized relationships between their average values) for estimating the coefficients of the processes' mutual influences. To test these methods, the adaptive model of the Sevastopol Bay ecosystem was constructed. The data of multi-year observations of the chemical processes in the bay were used for assimilating the observations of the nitrate and ammonia concentrations in the model. The data were assimilated both through their reducing to the dimension and scales of the variability corresponding to the model variable, and their including to the right parts of the model equations as the additional sources and sinks. The numerical experiments carried out using the integral model of the Sevastopol Bay ecosystem showed that application of the normalized relationships between their average values as the estimates of the processes' mutual influences permitted to reproduce the scenarios of all the processes in the ecosystem based on the limited observational data. The model response to the external effects at the constant and varying normalizing factors in the model coefficients is studied. It shows that the variable factors provide the model with higher sensitivity to the external effects.

Conclusions. The adaptive models of marine ecosystems constructed by the method of the adaptive balance of causes provide fast solutions' convergence to the stationary state. According to the laws of the matter balances' conservation in the biochemical reactions in substance transformations, the adaptive model tends to establishing dynamical balances in the external and intra-system influences. Therefore the proposed methods of estimating the intra-system relationships' coefficients in the marine ecosystem adaptive model permit to reconstruct the scenarios of those processes in which only their average values are known.

Keywords: ecosystem stationary state, adaptive balance of causes, variable normalization factors, marine ecosystem integral model, Sevastopol Bay, observation data assimilation.

Acknowledgments: the work was carried out on theme "Complex interdisciplinary investigations of the oceanologic processes conditioning functioning and evolution of the Black and Azov seas' coastal zones". Numerical experiments using the model of the Sevastopol Bay ecosystem were performed at financial support of RFBR and the Sevastopol Administration, grant 18-47-920001 "Investigation of the principles of constructing the adaptive models of ecological-economic systems and digital information technologies for managing the scenarios of sustainable development of economic complexes in the Sevastopol region".

For citation: Timchenko, I.E., Igumnova, E.M. and Svishchev, S.V., 2020. Modeling of Intra-System Relationships in the Adaptive Model of the Marine Environment Biochemical Processes. Physical Oceanography, 27(1), pp. 81-94. doi:10.22449/1573-160X-2020-1-81-94

DOI: $10.22449 / 1573-160 \mathrm{X}-2020-1-81-94$

(C) I.E. Timchenko, E.M. Igumnova, S.V. Svishchev, 2020

(C) Physical Oceanography, 2020

ISSN 1573-160X PHYSICAL OCEANOGRAPHY VOL. 27 ISS. 1 (2020) 


\section{Introduction}

The models of marine ecosystems describe processes in the sea that characterize the life cycles of living objects and the chemical reactions of substance transformation in the marine environment. Due to the complexity of these processes, in the mathematical modeling of ecosystems a problem of parameterization of the of biochemical process mutual influences exists. In order to solve it, it is necessary to use observational data. In a number of studies, the concept of the ecosystem stationary state was used for this purpose, adopting the hypothesis of an adaptive balance of mutual causes of processes when their values deviate from the stationary state [1]. In this case, it becomes possible to apply the adaptive balance of causes method [2-3] to construct the of the ecosystem model equations, which significantly simplifies them compared to the traditionally used parameterization of cause-effect relationships [4-12].

A hypothesis on maintaining a balance of causes allows us to express assessments of the influence coefficients in the model equations using the ratios of stationary values of the concentrations of the ecosystem simulated substances. In the present work, this approach is considered on the example of an integral model of the sea upper layer ecosystem. The aim of this work is to develop a method for assessing the influence coefficients in an adaptive ecosystem model, based on the relationship of the average values of simulated processes. Earlier in $[2,3,13]$, a method for normalizing dimensionless factors that appear in front of average relations, when the affecting functions are reduced to the variability scale of the ecosystem model main variable, was proposed. The factors were considered constant and were selected inversely proportional to the number of affecting functions. Particularly, in [3, 13] this method was applied in the problem of reconstructing the intra-annual variability of nitrification processes in the Sevastopol Bay. In this work we propose a modification of the method using variable normalizing factors that take into account the dynamics of biochemical substance concentrations in the marine environment. It is shown that both approaches make provide the assessment of effect of external factors on the variability of those biochemical processes for which there are no long-term series of observations but there are assessments of ecosystem stationary state.

\section{Adaptive balance of process interaction in the marine environment}

We suppose that according to long-term observations the average concentration values of a system of interconnected biochemical substances in the marine environment are known. We consider such averages to be the ecosystem model stationary state. The stationary state concept is a consequence of the assumption that the ecosystem is stable to the external impacts affecting it. Taking these averages as the system stationary state, we divide the temporal variability of biochemical processes into two components: stationary and dynamic. The modeling problem is to construct the equations for the dynamic component using information about the stationary one as more provided with archived observational data.

The systemic integrity principle [14] involves the construction of a system of ordinary differential equations for functions representing simulated processes. An important role is played by negative feedbacks, which make model variables 
dependent on the variation rates of these variables and therefore serve as factors of ecosystem stability. They automatically maintain the balances of internal and external effects in the ecosystem model. Due to the balances, the ecosystem has the property of living organism adaptation to the changing conditions of their existence $[9,11]$.

We denote the ecosystem model variables as $u_{i}$, and their (stationary) average values as $C_{i}$. If the variables $u_{i}$ are considered as products of reactions of biochemical processes interaction, then all other variables $u_{j}$ can be considered potential resources for the formation of these products. The equations of the reactions of resource transformation into the products should be subject to the mass conservation law, which links the deviations of concentrations of ecosystem variables from their stationary values:

$$
u_{i}-C_{i}=\sum_{j=1, j \neq i}^{n} a_{i j}\left(u_{j}-C_{j}\right)+A_{i} .
$$

The influence coefficients $a_{i j}$ for $n$ simulated processes take into account the contributions of resource concentrations to the formation of ecosystem products under effect of external impacts $A_{i}$ applied to it. Adaptation of variables to each other and to external effects, in which the material balance conservation law (1) is satisfied, should be incorporated into the structure of the model equations. This property is possessed by equations constructed by the adaptive balance of causes method [1-3]:

$$
\frac{d u_{i}}{d t}=2 r_{i} u_{i}\left[C_{i}-F_{i}^{+}\left(u_{i}, u_{j}, A_{i}\right)\right]
$$

where $r_{i}$ is relative rates of $u_{i}$ variables change; $F_{i}^{+}\left(u_{i}, u_{j}, A_{i}\right)$ are functionals from the variables $u_{i}$ arising from the conservation conditions of material balances of biological and chemical reactions of substance transformation in the marine environment (1):

$$
F_{\mathrm{i}}^{+}\left(u_{i}, u_{j}, A_{i}\right)=C_{i}=u_{i}-\sum_{j=1, j \neq i}^{n} a_{i j}\left(u_{j}-C_{j}\right)-A_{i} .
$$

As in general case each ecosystem variable is affected by $m$ of positive and $n-m$ of negative effects, the functionals (3) take the following form:

$$
F_{i}^{+}\left(u_{i}, u_{j}, A_{i}\right)=u_{i}-\sum_{k=1, k \neq i}^{m} a_{i k}\left(u_{k}-C_{k}\right)+\sum_{l=m+1, l \neq i}^{n} a_{i l}\left(u_{l}-C_{l}\right)-A_{i} .
$$

Substituting expression (4) into equations (2), we obtain the system of equations of the adaptive balance of causes method

$$
\frac{d u_{i}}{d t}=2 r_{i} u_{i}\left\{C_{i}-\left[u_{i}-\sum_{k=1, k \neq i}^{m} a_{i k}\left(u_{k}-C_{k}\right)+\sum_{l=m+1, l \neq i}^{n} a_{i l}\left(u_{l}-C_{l}\right)-A_{i}\right]\right\} .
$$


Marine ecosystem model constructed by means of modular equations (5) can be called adaptive, since its variables are automatically adjusted to each other and to external effects in such a way that the conditions for maintaining material balances are satisfied (1).

\section{Method of variable normalizing factors of the influence coefficients}

Since the influence coefficients determine the contribution of $u_{j}$ resource to the formation of product $u_{i}$, we assume that the ratios $u_{i}=a_{i j} u_{j}$ take place, as they show on average how much substances involved in the reactions interact with each other. The assumptions introduced allow us to express the influence coefficients in terms of the ratio of average values. To this end, we bring all the processes that affect the formation of the process $u_{i}$ to the dimension of this process by transformation:

$$
u_{i}=a_{i j}^{\prime} C_{i} C_{j}^{-1} u_{j}
$$

Then the coefficients $a_{i j}^{\prime}$ become dimensionless normalizing factors and the expression $C_{i} C_{j}^{-1} u_{j}$ plays the effect function role on the variability scale of $u_{i}$ variable.

In $[3,13]$ such a transformation was applied in order to reconstruct the scenario of intra-annual variability of nitrite concentration in the Sevastopol Bay. Observations of ammonium, nitrites and nitrates concentrations, as well as their average annual values, were used. The comparison of scenario with the observational data made it possible to confine ourselves in the first approximation to constant factors $a_{i j}^{\prime}$ at average value ratios as assessments of the influence coefficients in the adaptive model equations (5).

In this study a modified approach to determining the factors $a_{i j}^{\prime}$, when they become variables, since the normalization method takes into account not only the ratios of average values of the processes, but also the relative weight of the current effect is proposed. When normalizing the factors, the current positive definite values of the resources $u_{j}$ were used.

For example, for the case of a balance of three interconnected processes, we define variables normalizing factors $a_{i j}^{\prime}$ as follows:

$$
u_{1}=C_{1}+\frac{C_{2}^{-1} u_{2}}{C_{2}^{-1} u_{2}+C_{3}^{-1} u_{3}} \frac{C_{1}}{C_{2}} u_{2}^{\prime}+\frac{C_{3}^{-1} u_{3}}{C_{2}^{-1} u_{2}+C_{3}^{-1} u_{3}} \frac{C_{1}}{C_{3}} u_{3}^{\prime}
$$

If the equation has both positive and negative effects, in order to maintain this condition each group of effects must be normalized to 0.5. In general case, the system of the method equations with variable normalizing factors has the form 


$$
\begin{aligned}
& \frac{d u_{i}}{d t}=2 r_{i} u_{i}\left\{C_{i}-\left[u_{i}-0,5 \sum_{j=1, j \neq i}^{m} C_{j}^{-1} u_{j}\left(\sum_{k=1, j \neq i}^{m} C_{k}^{-1} u_{k}\right)^{-1} C_{i} C_{k}^{-1} u_{k}^{\prime}+\right.\right. \\
& \left.\left.+0,5 \sum_{j=m+1, j \neq i}^{n} C_{j}^{-1} u_{j}\left(\sum_{l=m+1, j \neq i}^{n} C_{l}^{-1} u_{l}\right)^{-1} C_{i} C_{l}^{-1} u_{l}^{\prime}-A_{i}\right]\right\}
\end{aligned} .
$$

\section{Adaptive version of the integrated model of the sea upper layer ecosystem}

In order to test the proposed methods for assessing the influence coefficients, we used a modified ecosystem model of Fasham, Ducklow, and McKelvie [12] for the nitrogen cycle in the sea upper layer (hereinafter referred to as the Fasham model). The modification consisted in the fact that the calculated parameters of classic Fasham model were supplemented by three previously disregarded processes of dissolved organic matter destruction with the formation of ammonium ions, dissolved organic matter destruction with the formation of nitrates and a simplified nitrification process (ammonium oxidation to nitrates).

As external sources of effect on the simulated processes one can include information on the surface layer temperature and chlorophyll $a$ concentration obtained from the sea upper layer satellite observations, as well as the data on transport and diffusion of substances obtained from calculations using hydrodynamic models [6, 15]. The scheme of intra-system relationships in the adaptive model of biochemical processes is represented in Fig. 1.

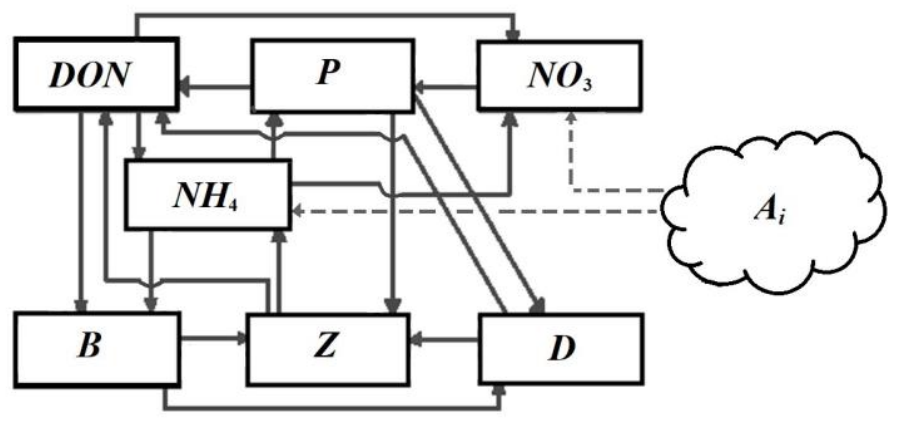

F i g. 1. Scheme of basic intra-system relationships in the integral model of biochemical processes in the sea upper layer based on the Fasham, Ducklow and McKelvie model [12]

In the scheme the following notations of parameters were used: $P$ is phytoplankton concentration; $Z$ is zooplankton concentration; $B$ is bacterioplankton concentration; $\mathrm{NO}_{3}$ and $\mathrm{NH}_{4}$ is the content of nitrogen inorganic forms (nitrate ions and ammonium ions) in the water; $D O N$ is a concentration of nitrogen organic forms; $D$ is a content of inert organic matter (detritus); $A_{i}$ is external effects on the ecosystem caused by various factors, including the marine environment dynamics. All model variables are non-negative and are expressed in milligrams of nitrogen per cubic meter.

To construct the model, we use the system of equations (8). In the equation for phytoplankton concentration the variation rate of concentration is determined by PHYSICAL OCEANOGRAPHY VOL. 27 ISS. 1 (2020) 
the consumption of nutrients by phytoplankton cells $a_{14} \mathrm{NO}_{3}+a_{15} \mathrm{NH}_{4}$, expenditures on vital activity $\left(-a_{16} D O N\right)$ and natural mortality $\left(-a_{17} D\right)$ as well as grazing of phytoplankton by zooplankton $\left(-a_{12} Z\right)$ :

$$
\begin{aligned}
& \frac{d P}{d t}=2 r_{P} P\left\{C_{P}-\left[P-C_{P}\left(a_{14} C_{N O_{3}}^{-1} N O_{3}^{\prime}+a_{15} C_{N H_{4}}^{-1} N H_{4}^{\prime}-\right.\right.\right. \\
& \left.\left.\left.-a_{12} C_{Z}^{-1} Z^{\prime}-a_{16} C_{D O N}^{\prime-1} D O N^{\prime}-a_{17} C_{D}^{-1} D^{\prime}\right)\right]\right\}
\end{aligned}
$$

The processes of phytoplankton sedimentation and its removal outside the system were not taken into account in this model. The limitation of phytoplankton biomass growth rate by other nutrients (phosphates, silicates), temperature and illumination was not taken into account.

The variation rate of zooplankton concentration is determined by the processes of its growth due to nutrition of phyto- and bacterioplankton organisms and detritus $\left(a_{21} P+a_{23} B+a_{27} D\right)$, as well as expenses on vital functions $\left(-a_{25} \mathrm{NH}_{4}-a_{26} \mathrm{DON}\right)$. The zooplankton grazing by organisms of higher trophic levels was not taken into account in this model. The equation for zooplankton concentration was used in the following form:

$$
\begin{aligned}
& \frac{d Z}{d t}=2 r_{Z} Z\left\{C_{Z}-\left[Z-C_{Z}\left(a_{21} C_{P}^{-1} P^{\prime}+a_{23} C_{B}^{-1} B^{\prime}+a_{27} C_{D}^{-1} D^{\prime}-\right.\right.\right. \\
& \left.\left.\left.-a_{25} C_{N H_{4}}^{-1} N H_{4}^{\prime}-a_{26} C_{D O N}^{-1} D O N^{\prime}\right)\right]\right\}
\end{aligned}
$$

Variation rate of bacterioplankton concentration is determined by the consumption of ammonium and dissolved organic matter by the bacterioplankton cells $\left(a_{35} \mathrm{NH}_{4}+a_{36} \mathrm{DON}\right)$, its grazing by zooplankton $\left(-a_{32} \mathrm{Z}\right)$ and expenditures on natural mortality $\left(-a_{37} D\right)$ :

$$
\begin{aligned}
& \frac{d B}{d t}=2 r_{B} B\left\{C_{B}-\left[B-C_{B}\left(a_{35} C_{N H_{4}}^{-1} N H_{4}^{\prime}+\right.\right.\right. \\
& \left.\left.\left.+a_{36} C_{D O N}^{-1} D O N^{\prime}-a_{32} C_{Z}^{-1} Z^{\prime}-a_{37} C_{D}^{-1} D^{\prime}\right)\right]\right\}
\end{aligned}
$$

Inorganic forms of nitrogen are spent on the phytoplankton growth - $\left(a_{14} \mathrm{NO}_{3}\right)$ and $\left(a_{15} \mathrm{NH}_{4}\right)$. The pool of nutrients is replenished due to the excretion of undigested part of food $\left(a_{52} Z\right)$ by zooplankton and dissolved organic matter destruction with the formation of nitrates $\left(a_{46} D O N\right)$ and ammonium $\left(a_{56} D O N\right)$. In addition, there is a redistribution of substance from ammonium $\left(-a_{54} \mathrm{NO}_{3}\right)$ to nitrates $\left(+a_{45} \mathrm{NH}_{4}\right)$ during the nitrification process:

$$
\begin{aligned}
& \frac{d \mathrm{NO}_{3}}{d t}=2 r_{\mathrm{NO}_{3}} \mathrm{NO}_{3}\left\{\mathrm{C}_{\mathrm{NO}_{3}}-\left[\mathrm{NO}_{3}-\mathrm{C}_{\mathrm{NO}_{3}}\left(a_{45} \mathrm{C}_{\mathrm{NH}_{4}}^{-1} \mathrm{NH}_{4}^{\prime}+\right.\right.\right. \\
& \left.\left.\left.+a_{46} \mathrm{C}_{\mathrm{DON}}^{-1} \mathrm{DON}^{\prime}-a_{41} C_{P}^{-1} P^{\prime}\right)\right]\right\}
\end{aligned}
$$




$$
\begin{aligned}
& \frac{d N H_{4}}{d t}=2 r_{N H_{4}} N_{4}\left\{C_{N H_{4}}-\left[N H_{4}-C_{N H_{4}}\left(a_{52} C_{Z}^{-1} Z^{\prime}+a_{56} C_{D O N}^{-1} D O N^{\prime}-\right.\right.\right. \\
& \left.\left.\left.-a_{51} C_{P}^{-1} P^{\prime}-a_{53} C_{B}^{-1} B^{\prime}-a_{54} C_{N O_{3}}^{-1} N O_{3}^{\prime}\right)\right]\right\}
\end{aligned} .
$$

The concentration variation rate of nitrogen dissolved organic forms is determined by the release of vital activity metabolites $\left(a_{61} P+a_{62} Z\right)$ by phytoplankton and zooplankton and the decomposition (mineralization) of detritus to dissolved organic matter $\left(a_{67} D\right)$, as well as dissolved organic matter consumption by bacterioplankton $\left(-a_{63} B\right)$ and the destruction of dissolved organic matter with the formation of nitrates $\left(-a_{64} N_{3}\right)$ and ammonium $\left(-a_{65} N_{4}\right)$ :

$$
\begin{aligned}
& \frac{d D O N}{d t}=2 r_{D O N} D O N\left\{C_{D O N}-\left[D O N-C_{D O N}\left(a_{61} C_{P}^{-1} P^{\prime}+a_{62} C_{Z}^{-1} Z^{\prime}+a_{67} C_{D}^{-1} D^{\prime}-\right.\right.\right. \\
& \left.\left.\left.-a_{63} C_{B}^{-1} B^{\prime}-a_{64} C_{N O_{3}}^{-1} N O_{3}^{\prime}-a_{65} C_{N H_{4}}^{-1} N H_{4}^{\prime}\right)\right]\right\}
\end{aligned} .
$$

The detrital pool is replenished due to phytoplankton and bacterioplankton natural mortality $\left(a_{71} P+a_{73} B\right)$, and is consumed as a result of bacterial decomposition (mineralization) of detritus to dissolved organic matter $\left(-a_{76} D O N\right)$ and zooplankton nutrition $\left(-a_{72} Z\right)$ :

$$
\begin{aligned}
& \frac{d D}{d t}=2 r_{D} D\left\{C_{D}-\left[D-C_{D}\left(a_{71} C_{P}^{-1} P^{\prime}+a_{73} C_{B}^{-1} B^{\prime}-\right.\right.\right. \\
& \left.\left.\left.-a_{72} C_{Z}^{-1} Z^{\prime}-a_{76} C_{D O N}^{-1} D O N^{\prime}\right)\right]\right\}
\end{aligned}
$$

The finite-difference representation of the system of equations (9)-(15) under the additional condition $2 \Delta t r_{i} C_{i}=1$, where $\Delta t$ is a time step of calculations, takes the following general form:

$$
u_{i}^{k+1}=2 u_{i}^{k}\left\{1-\frac{1}{2 C_{i}}\left[u_{i}^{k}-\sum_{j=1, j \neq i}^{n} a_{i j}\left(u_{j}^{k}-C_{j}\right)-A_{i}^{k}\right]\right\} .
$$

The system of equations was supplemented by logical conditions that controlled the variability limits of the model variables:

$$
u_{i}=I F\left[u_{i}<0 ; 0 ; \operatorname{IF}\left(u_{i}>2 C_{i} ; 2 C_{i} ; u_{i}\right)\right]
$$




\section{Assimilation of hydrochemical observation data in the integral model of the Sevastopol bay ecosystem}

As an example, we consider the application of the integrated ecosystem model (9)-(15) to observations of biochemical processes in the Sevastopol Bay. The data on the content of nitrogen inorganic forms (nitrate ions and ammonium ions) in the water were taken from $[3,13]$ and are consistent with long-term values [1618]. The following average values for the concentrations of phytoplankton, zooplankton, bacterioplankton, nitrates, ammonium, dissolved organic forms of nitrogen and detritus, respectively, were obtained from the archival data of longterm observations of biochemical processes in the bay: $37.74 ; 18.87 ; 12.0 ; 42.35$; $5.60 ; 18.0$ and $15.0 \mathrm{mgN} / \mathrm{m}^{3}$. These average values are taken as the ecosystem stationary state and their normalized ratios are used in the expressions for the influence coefficients in the finite-difference representations (16) of model equations of (9) - (15). The calculations were performed at 300 steps in time (dimensionless days).

The experiment results are represented in Fig. 2, $a$ and $b$.

A comparison of the scenarios revealed the fact that both options provide the establishment of the specified average values of processes already at the first 15 steps of iterations. The greater the initial deviation from the simulated substance average concentration, the longer the transition process of establishing a stationary state. The nature of transient attenuation in the case of constant factors is aperiodic, and in the case of variable factors it is periodic. As follows from Fig. 2, $c$ and $d$, the graphs for dissolved organic forms of nitrogen and bacterioplankton, the identification of variable factors in the ecosystem model equations occurred simultaneously with the calculation of scenarios of these processes. Thus, during the iterations the variable factors provided a differentiated recording of current values of the resources that form the values of the simulated processes.

The variable factor method was applied to assimilate the data of long-term observations of nitrate and ammonium concentrations in the Sevastopol Bay in the ecosystem model (9)-(15). In Fig. 3, $a$ and $b$ the measured concentrations are shown by circles and the results of their polynomial approximation are shown by dashed lines. In Fig. 3, $c$ and 3, $d$ the graphs of the averaged intra-annual variation of nitrate and ammonium concentrations, obtained by moving averaging of time series of observations over a time interval of 30 days are given. These averaged series of observations were used in experiments on assimilation of observations in an ecosystem model.

Unlike the classical approaches to data assimilation [19-21], the adaptive models are characterized by a simpler way of observational data assimilation in them [2, 3, 13]. Observations are included as additional source functions in parentheses of model equations (9)-(15) after they are brought to the corresponding variability interval of the variable by transformation (6). The assimilation results of nitrates and ammonium observation time series in the model, depicted in Fig. 3, $c$ and $d$ are presented in Fig. 4, $a$ and $b$. It should be pointed out that the adaptive model turned out to be sensitive to external effects of ammonium and nitrate concentration observations. Scenarios of phyto-, zoo- and bacterioplankton concentrations shown in Fig. 4, $a$ deviate from their average values by $20-40 \%$. 

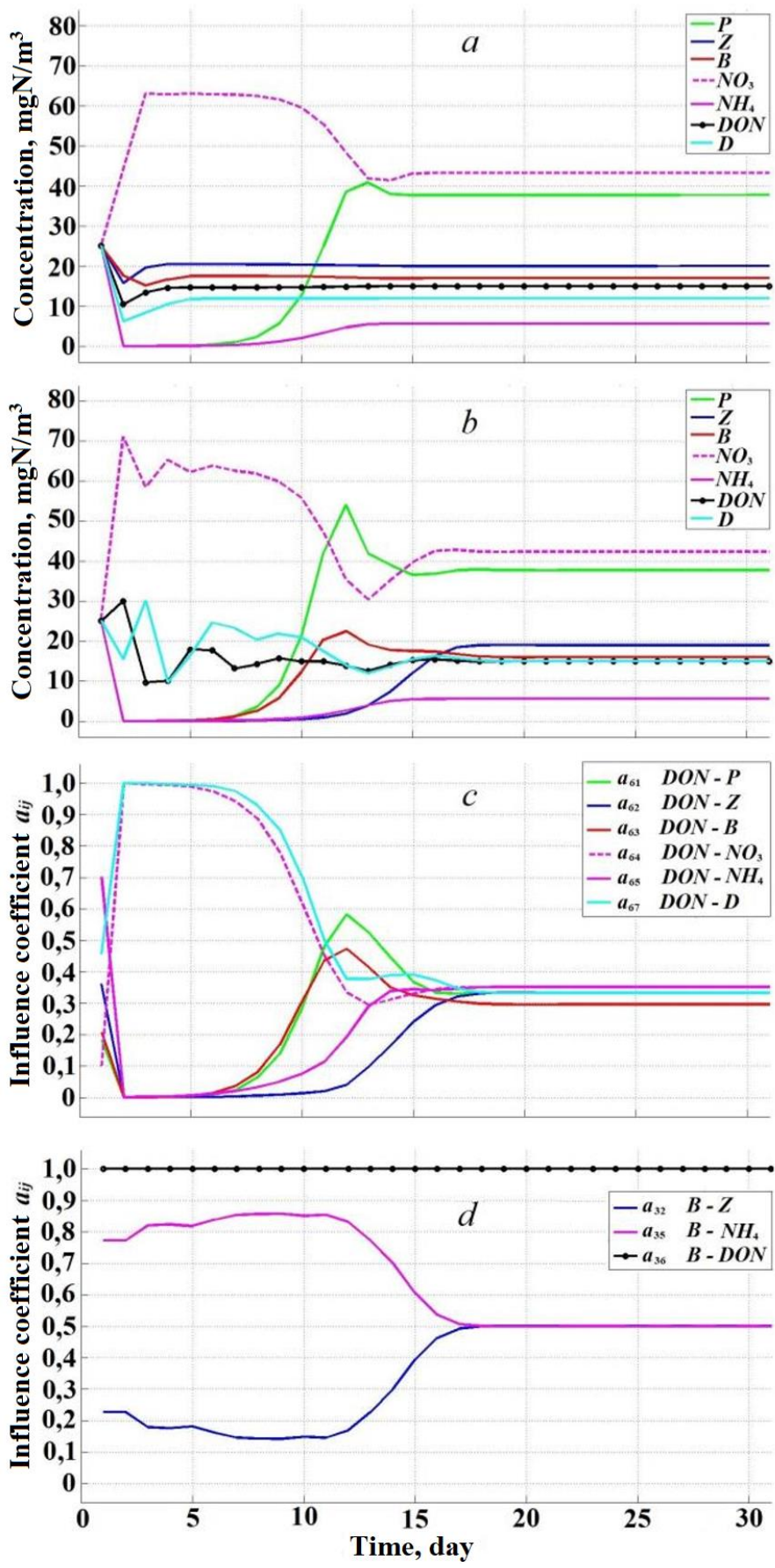

F i g. 2. Convergence to the stationary state of the substance concentrations' scenarios at constant $(a)$ and varying $(b)$ normalizing factors; identification of the influence coefficients at the varying factors in the equations for $\mathrm{DON}(c)$ и $\mathrm{B}(d)$ 


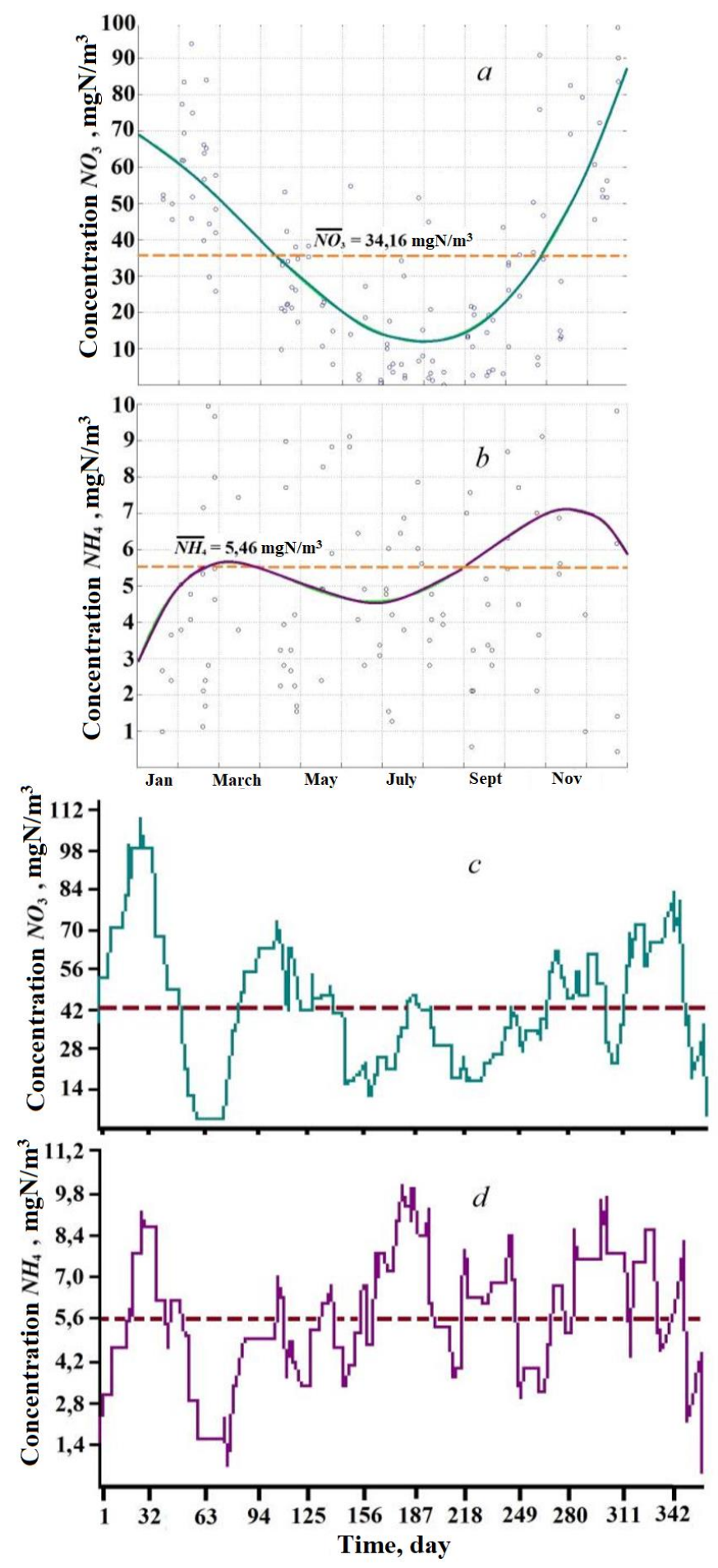

F i g. 3. Data of multi-year observations of the nitrate $(a)$ and ammonium $(b)$ concentrations in the Sevastopol Bay; graphs of average multi-year monthly average variability of $\mathrm{NO}_{3}(c)$ and $\mathrm{NH}_{4}(d)$ concentrations resulted from smoothing the nitrate and ammonia observations using 30 values of time series 

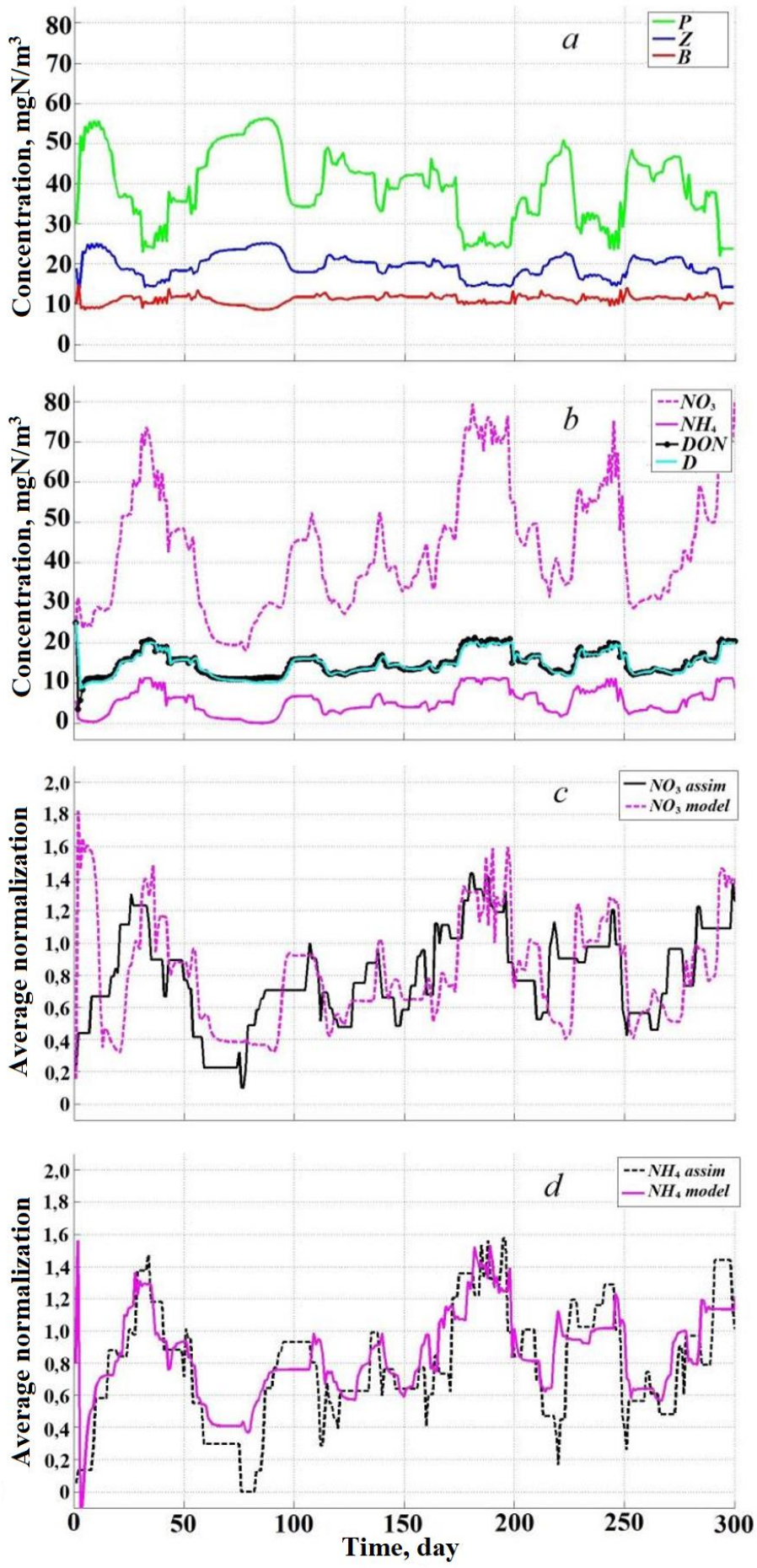

F i g. 4. Results of assimilation of time series of the nitrate and ammonia observations shown on Fig. 3, $c$ and $d: a$ and $b$ - scenarios of all the model reproduced processes (graphs DON and D coinscide); $c$ and $d$-the assimilated observation data ( $\mathrm{NO}_{3}$ assim and $\mathrm{NH}_{4}$ assim) and the model reproduced results ( $\mathrm{NO}_{3}$ model and $\mathrm{NH}_{4}$ model) 
It was of interest to compare the observation data of nitrate and ammonium concentrations with the scenarios of these variables reconstructed by the model based on the results of assimilation of observations (Fig. 4, $c$ and $d$ ). Visual assessment confirms their close match. However, it should be taken into account that the nitrate and ammonium concentration scenarios are formed not only by the direct effect of assimilating observations on them, but also by multiple feedbacks with other model variables. The variances of the differences between the observations and the scenarios of nitrate and ammonium concentrations were $8.3 \%$ for nitrates and $5.6 \%$ for ammonium from the variances of the corresponding observation time series.

\section{Conclusion}

The construction of integral models of marine ecosystems by the adaptive balance of causes method is based on the use of logistic type equations (5), which provide quick convergence of solutions to a stationary state due to negative secondorder feedbacks available in each of the model equations. Similar models describe the ecosystem response to external effects. The essence of the reaction is the mutual adaptation of the model variables to each other and to external effects. An important property of adaptive models is the preservation of the material balances of biological and chemical substance transformation reactions in the marine environment. Following the material balance conservation laws, the adaptive model tends to establishment of dynamic balances of external and intra-system effects.

The presented parameterization of intra-system effects is of fundamental importance for striking the material balances in the modeling of marine ecosystems using the adaptive balance of causes method. In the adaptive models the traditional parameterization of relationships between biochemical processes, which is based on attracting large amounts of information and a number of bulky formulas, can be used. However, in such a case the main advantage of adaptive models over traditional ones (the simplicity of the system of modular equations and the guaranteed stability of their solutions) will be significantly weakened. Therefore, the idea of using the known stationary state of an adaptive model to obtain simple assessments of the influence coefficients realized in this work is of practical interest.

Computational experiments carried out with the integrated ecosystem model of the Sevastopol Bay confirmed the hypothesis that the use of normalized ratios of average process values as assessments of mutual effects of processes allows reproducing scenarios of processes in the ecosystem. The reaction of the model to external effects with constant and variable normalizing factors, which showed that variable factors provide higher model sensitivity to external effects, is studied.

\section{REFERENCES}

1. Timchenko, I.E., Igumnova, E.M. and Timchenko, I.I., 2016. Adaptive Balance Models for Environmental-Economic Systems. CreateSpace Independent Publishing Platform, 486 p. 
2. Timchenko, I.E., Lazarchuk, I.P. and Igumnova, E.M., 2017. Assimilation of the Observational Data in the Marine Ecosystem Adaptive Model at the Known Mean Values of the Processes in the Marine Environment. Physical Oceanography, (5), pp. 71-86. doi:10.22449/1573-160X-2017-5-71-86

3. Timchenko, I.E., Igumnova, E.M. and Svishchev, S.V., 2019. Application of the Principles of the Marine Ecosystems' Adaptive Modeling to the Hydrochemical Observations in the Sevastopol Bay. Physical Oceanography, 26(1), pp. 63-76. doi:10.22449/1573-160X2019-1-63-76

4. Voinov, A., 2008. Systems Science and Modeling for Ecological Economics. New York: Academic Press, 432 p.

5. Radtke, H. and Burchard, H., 2015. A Positive and Multi-Element Conserving Time Stepping Scheme for Biogeochemical Processes in Marine Ecosystem Models. Ocean Modelling, 85, pp. 32-41. doi:10.1016/j.ocemod.2014.11.002

6. Korotaev, G.K., Oguz, T., Dorofeyev, V.L., Demyshev, S.G., Kubryakov, A.I. and Ratner, Yu.B., 2011. Development of Black Sea Nowcasting and Forecasting System. Ocean Science, 7(5), pp. 629-649. doi:10.5194/os-7-629-2011

7. Podgornyj, K.A., 2012. Investigation of the Properties of Spatially Homogeneous Mathematical Model of the Four-Component Plankton System. Mathematical Biology and Bioinformatics, 7(1), pp. 299-321. doi:10.17537/2012.7.299 (in Russian).

8. Long, R.D., Charles, A. and Stephenson, R.L., 2015. Key Principles of Marine EcosystemBased Management. Marine Policy, 57, pp. 53-60. http://dx.doi.org/10.1016/j.marpol.2015.01.013

9. Platt, T., Mann, K.H. and Ulanowicz, R.E., eds., 1981. Mathematical Models in Biological Oceanography. Paris: The UNESCO Press, 157 p.

10. Costanza, R., de Groot, R., Sutton, P., van der Ploeg, S., Anderson, S.J., Kubiszewski, I., Farber, S. and Turner, R.K., 2014. Changes in the Global Value of Ecosystem Services. Global Environmental Change, 26, pp. 152-158. http://dx.doi.org/10.1016/j.gloenvcha.2014.04.002

11. Murray, J.D., 2003. Mathematical Biology II: Spatial Models and Biomedical Applications. New-York: Springer, 814 p. https://doi.org/10.1007/b98869

12. Fasham, M.J.R., Ducklow, H.W. and McKelvie S.M., 1990. A Nitrogen-Based Model of Plankton Dynamics in the Oceanic Mixed Layer. Journal of Marine Research, 48(3), pp. 591639. https://doi.org/10.1357/002224090784984678

13. Svishchev, S.V., 2018. Adaptive Modeling of Nitrification in the Sevastopol Bay. Ecological Safety of Coastal and Shelf Zones of Sea, (2), pp. 60-65. doi:10.22449/2413-5577-2018-2-6065 (in Russian).

14. Moiseev, N.N., Aleksandrov, V.V. and Tarko, A.M., 1985. [The Man and the Biosphere. Experience of System Analysis and Experiments with Models]. Moscow: Nauka, 271 p. (in Russian).

15. Sarkisyan, A.S., 2016. Main Directions in the Simulation of Physical Characteristics of the World Ocean and Seas. Izvestiya, Atmospheric and Oceanic Physics, 52(4), pp. 335-340. doi:10.1134/S0001433816040101

16. Orekhova, N.A., Romanov, A.S. and Khoruzhiy, D.S., 2011. Interannual Changes in the Concentration of Nutrients in the Sevastopol Region for the Period 2006-2010. In: MHI, 2011. Ecological Safety of Coastal and Shelf Zones and Comprehensive Use of Shelf Resources. Sevastopol, MHI. Iss. 25 (1), pp. 192-199 (in Russian).

17. Orekhova, N.A. and Varenik, A.V., 2018. Current Hydrochemical Regime of the Sevastopol Bay. Physical Oceanography, 25(2), pp. 124-135. doi:10.22449/1573-160X-2018-2-124-135

18. Myslina, M.A. and Varenik, A.V., 2019. Inorganic Nitrogen Deposition with the Atmospheric Precipitations to the Sevastopol Bay in 2015-2016. Ecological Safety of Coastal and Shelf Zones of Sea, (1), pp. 78-82. doi:10.22449/2413-5577-2019-1-78-82 (in Russian). 
19. Marchuk, G.I. and Zalesny, V.B., 1993. A Numerical Technique for Geophysical Data Assimilation Problems Using Pontryagin's Principle and Splitting-Up Method. Russian Journal of Numerical Analysis and Mathematical Modelling, 8(4), pp. 311-326. doi:10.1515/rnam.1993.8.4.311

20. Robinson, A.R. and Lermusiaux, P.F.J., 2000. Overview of data assimilation. Harvard Reports in Physical/Interdisciplinary (Ocean Science). Cambridge, Massachusetts: Harvard

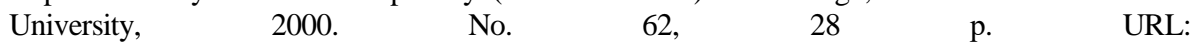
http://robinson.seas.harvard.edu/PAPERS/red_report_62.html [Accessed: 14 November 2019].

21. Mizyuk, A.I., Knysh, V.V., Kubryakov, A.I. and Korotaev, G.K., 2009. Assimilation of the Climatic Hydrological Data in the $\sigma$-Coordinate Model of the Black Sea by the Algorithm of Adaptive Statistics. Physical Oceanography, 19(6), pp. 339-357. doi:10.1007/s11110-0109058-2

About the authors:

Igor E. Timchenko, Deputy Chief Editor, Head of System Analysis Department, Marine Hydrophysical Institute of RAS (2 Kapitanskaya Str., Sevastopol, 299011, Russian Federation), Dr.Sci. (Phys.-Math.), Professor, ResearcherID: A-8650-2017, timchenko.syst.analysis@mhi-ras.ru

Ekaterina M. Igumnova, Leading Engineer, Marine Hydrophysical Institute of RAS (2 Kapitanskaya Str., Sevastopol, 299011, Russian Federation), SPIN-code: 5950-7785 Author ID: 861018, igumnova.syst.analysis@mhi-ras.ru

Sergey V. Svishchev, Junior Engineer-Researcher, Marine Hydrophysical Institute of RAS (2 Kapitanskaya Str., Sevastopol, 299011, Russian Federation), ResearcherID: T-1962-2018, ORCID ID: 0000-0003-4673-7609, sergsvishchev09@gmail.com

Contribution of the co-authors:

Igor E. Timchenko - the idea of the adaptive balance of causes method and the derivation of equations of marine ecosystem adaptive model

Ekaterina M. Igumnova - carrying out the calculations on the model and the analysis of simulation results

Sergey V. Svishchev - discussion of the method and software implementation of the hydrochemical part of marine ecosystem adaptive model

All the authors have read and approved the final manuscript.

The authors declare that they have no conflict of interest. 